\title{
Kinetic Properties of Extracted Lactate Dehydrogenase and Creatine Kinase from Mouse Embryonic Stem Cell- and Neonatal-derived Cardiomyocytes
}

\author{
Roseata Zonouzi $^{1,2}$, Saeid Kazemi Ashtiani ${ }^{1, \#}$, Saman Hosseinkhani ${ }^{3}$ and Hossein Baharvand ${ }^{1, *}$ \\ ${ }^{1}$ Department of Stem Cells, Royan Institute, ${ }^{2}$ Department of Biology, Islamic Azad University, Sciences and Research Campus, \\ ${ }^{3}$ Department of Biochemistry, Faculty of Sciences, Tarbiat Modaress University, Tehran, Iran
}

Received 18 January 2006, Accepted 14 April 2006

\begin{abstract}
Embryonic stem cells (ESCs), representing a population of undifferentiated pluripotent cells with both self-renewal and multilineage differentiation characteristics, are capable of spontaneous differentiation into cardiomyocytes. The present study sought to define the kinetic characterization of lactate dehydrogenase (LDH) and creatine kinase (CK) of ESC- and neonatal-derived cardiomyocytes. Spontaneously differentiated cardiomyocytes from embryoid bodies (EBs) derived from mouse ESC line (Royan B1) and neonatal cardiomyocytes were dispersed in a buffer solution. Enzymes were extracted by sonication and centrifugation for kinetic evaluation of LDH and CK with spectrophotometric methods. While a comparison between the kinetic properties of the LDH and CK of both groups revealed not only different Michaelis constants and optimum temperatures for LDH but also different Michaelis constants and optimum $\mathrm{pH}$ for $\mathrm{CK}$, the $\mathrm{pH}$ profile of $\mathrm{LDH}$ and optimum temperature of $\mathrm{CK}$ were similar. In defining some kinetic properties of cardiac metabolic enzymes of ESC-derived cardiomyocytes, our results are expected to further facilitate the use of ESCs as an experimental model.
\end{abstract}

Keywords: Cardiomyocyte, Creatine kinase, Differentiation, Embryonic stem cells, Enzyme activity, Lactate dehydrogenase

\footnotetext{
"Dr. Saeid Kazemi Ashtiani unexpectedly passed away on 4 January, 2006 of a heart attack. His demise has been a painful loss to our department and the stem cell society of Iran. This article is dedicated to him, a great stem cell biologist, a wonderful colleague, and an inspirational advocate of human stem cell research in Iran.
}

*To whom correspondence should be addressed.

Tel: 98-21-22172330; Fax: 98-21-22409314

E-mail: Baharvand50@yahoo.com

\section{Introduction}

The establishment of embryonic stem cells (ESCs) has given rise to a new experimental approach in the field of mamalian biology. Often derived from the inner cell mass of the blastocyst (Evans and Kaufman, 1981; Martin, 1981), ESCs exhibit high proliferative capabilities and can form virtually any specialized tissue upon the induction of differentiation. ESCs' embryonic origins, however, render them different from other stem cells in that they retain the potential to generate derivatives of all cell lineages, including the germ line (Labosky et al., 1994). In vitro murine ESCs can be propagated indefinitely in an undifferentiated state, yet they retain the capacity to differentiate into all mature somatic phenotypes upon specific induction cues. These cells, therefore, have the potential to provide an unlimited supply of cells for transplant purposes in the treatment of certain diseases. A breakthrough in this field came from the establishment of human ESCs (Thomson et al., 1998). Differentiation is promoted when ESCs are cultured on a non-adhesive substrate where they develop into multicellular aggregates called embryoid bodies (EBs). Culturing the embryoid bodies for a few days and then plating them on an adhesive substrate results in the appearance of such multiple cell types as skeletal muscle, cardiomyocytes and neuronal cells in the outgrowths of EBs (Smith, 2001). The aforementioned properties afford us the opportunity to utilize ESCs and derivatives as a model system for studying the effects of drug and environmental factors on differentiation, cell therapy, functional genomics and developmental biology. ESC-derived cardiomyocytes may be a good candidate population for cell therapy, but this and other potential applications of ESCderived cardiomyocytes are largely dependent upon a better understanding of their metabolic conditions, gene expression and cytoplasmic agents. Although the morphology, ultrastructure, electrophysiology, pharmacology and expression of cardiacspecific genes have been investigated (Saks et al., 1980; Maltsev et al., 1993; Maltsev et al., 1994; Hescheler et al., 1997; Kenneth et al., 2002; Baharvand et al., 2005), such 
metabolic conditions as information on enzymes of ESCderived cardiomyocytes are yet to be explored so that the resultant data could be used in assessing the function and development of differentiated cardiomyocytes. For example, lactate dehydrogenase (L-lactate: $\mathrm{NAD}^{+}$oxidoreductase, EC $1,1,1,27 ; \mathrm{LDH})$ and creatine kinase (ATP:creatine N-phosphory transferase, EC 2, 7, 3, 2; CK) play an important role in the intracellular energy transport of cardiomyocytes (Saks et al., 1980). These enzymes have various isoforms with different kinetic properties (Dawson et al., 1967; Li, 1998). LDH is a cytoplasmic enzyme catalyzing the interconversion of Llactate and pyruvate with nicotinamide adenine dinucleotide $\left(\mathrm{NAD}^{+}\right)$as a coenzyme and a contributing factor to $\mathrm{NAD}^{+}$ regenaration. $\mathrm{CK}$ is another enzyme having been suggested to play a key role in energy metabolism by replenishing ATP through the transfer of the phosphoryl group from phosphocreatine (CrP) to ADP (buffer function) and facilitating intracellular energy transduction (creatine kinase shuttle hypothesis). In the present study, we performed a comparative study between mouse ESC- and neonatal-derived cardiomyocytes based on the kinetic properties of two cardiac metabolic enzymes: LDH and CK.

\section{Materials and Methods}

Culture of embryonic stem cells. Cells of the murine embryonic cell line Royan B1 were grown on a feeder layer of primary mouse embryonic fibroblasts (MEF) in tissue culture flasks as previously described (Baharvand and Matthaei, 2004). The cells were cultivated on gelatin $(0.1 \%$, Sigma, G2500) coated plastic flasks (Falcon) in ES medium containing Dulbeco's modified Eagle's medium (DMEM, Gibco, 10829-018) supplemented with 15\% fetal calf serum (Gibco, 16141-079), $0.1 \mathrm{mM}$ beta-mercaptoethanol (Sigma, M7522), $2 \mathrm{mM}$ glutamine (Gibco, 15039-027), $0.1 \mathrm{mM}$ non-essential amino acids (Gibco, 11140-035), and $1000 \mathrm{IU} / \mathrm{ml}$ leukemia inhibitory factor (LIF, Chemicon, ESGRO, ESG1107).

Differentiation of embryonic stem cells into cardiomyocytes. The ESCs were differentiated into spontaneously beating cardiomyocytes as previously described (Maltsev et al., 1994). Briefly, the main steps of differentiation comprised the following: 1) cultivating a definite number of cells (800) in "hanging drops" $(20 \mu \mathrm{l})$ as embryoid bodies (EBs) for 2 days, 2) cultivating as suspension in bacterial dishes for 5 days, and 3) plating of 7 day-old (7d) EBs on gelatin-coated 24-well plates in DMEM, supplemented with $15 \%$ FCS; $2 \mathrm{mM}$ glutamine; and $0.1 \mathrm{mM}$ non-essential amino acids. Cardiomyocytes appeared in the EB outgrowths in the form of spontaneously contracting cell clusters. Ten days after the plating of the seven-day EBs (day 7+10), the beating areas were mechanically dissected using a mouth-controlled pipette under phase contrast microscopy (Nikon) before they were washed in phosphate buffered saline (PBS) twice.

Isolation of neonatal mouse cardiomyocytes. First, cardiomyocytes were isolated from 2-4-day-old mice by modifying the procedure of Chlopcikova et al. (2001). Whole hearts were isolated and transferred into a cold balanced salt solution containing $20 \mathrm{mM}$ HEPES, $1 \mathrm{mM} \mathrm{NaH} \mathrm{PO}_{4}, 5.4 \mathrm{mM} \mathrm{KCl} 120 \mathrm{mM} \mathrm{NaCl}, 5.5 \mathrm{mM}$ glucose and $0.8 \mathrm{mM} \mathrm{MgSO}_{4}$ in $\mathrm{pH}$ 7.3-7.4. Subsequently, the hearts were squeezed gently with forceps to expel the blood from the lumen. The tissues were then minced with an $18 \mathrm{G}$ needle twice and washed with $0.16 \mathrm{mg} / \mathrm{ml}$ heparin solution in PBS to remove blood cells. After that, the myocardial cells were dispersed by the addition of balanced salt solution containing trypsin $(0.2 \%)$ before they were stirred at $37^{\circ} \mathrm{C}$ in a water bath for $20 \mathrm{~min}$. The supernatant was removed and discarded. The pieces of tissue were incubated with fresh solution containing trypsin for $20 \mathrm{~min}$ at $37^{\circ} \mathrm{C}$. The supernatant having been collected, the digestion steps were repeated five times and the cell suspensions from each digestion were pulled and centrifugated at $1800 \mathrm{rpm}$ for $20 \mathrm{~min}$. The cells were resuspended in DMEM, 15\% FCS, 1\% L-glutamin and 1\% non-essential amino acid. Next, cardiomyocytes were loaded onto discontinuous percoll gradient (1.082-1.062) prepared in PBS. After centrifugation at $6000 \mathrm{rpm}$ for $30 \mathrm{~min}$, the cell layer was collected, washed in medium and plated on a gelatin $(0.1 \%)$-coated culture flask for 1.5 $2 \mathrm{~h}$ to allow the differential attachment of non-myocardial cells. The non-adhesive myocytes were subsequently centrifuged at 1800 rpm for $20 \mathrm{~min}$. Finally, the cardiomyocytes were washed and resuspended in PBS and used for enzyme extraction.

Immunocytochemistry. Beating areas of five to ten embyroid bodies at day $7+10$ were mechanically isolated with a pipette and washed in $\mathrm{Ca}^{2+}$ - and $\mathrm{Mg}^{2+}$-free PBS followed by incubation with trypsin/EDTA solution for $3 \mathrm{~min}$. The isolated cells were resuspended in culture medium and plated into tissue culture dishes. After 2 days of incubation, the beating cells were used for immunostaining. The cells were rinsed twice with PBS, fixed with methanol/aceton $(3: 1)$ at $-20^{\circ} \mathrm{C}$ and incubated with the anti- $\alpha$-actinin $(1: 800$, Sigma, A7811) for $60 \mathrm{~min}$ at $37^{\circ} \mathrm{C}$ in a humid chamber. At the end of the incubation time, the cells were rinsed 3 times with PBS and incubated with a fluorescence isothiocyanate (FITC)-conjugated anti-mouse IgG (Sigma, F9006) diluted in PBS (1:100) for $60 \mathrm{~min}$ at $37^{\circ} \mathrm{C}$. The cells, having been rinsed three times with PBS, were analyzed under a fluorescent microscope (Nikon, Japan).

Enzymes preparation for assay. The $7+10 \mathrm{~d}$ ESC- and neonatalderived cardiomyocytes were sonicated on ice in PBS (pH 7.4) containing $5 \mathrm{mM} \beta$-mercaptoethanol and 5mM PMSF (Phenyl Methane Sulfonyl Fluoride, a protease inhibitor). After centrifugation at $14,000 \mathrm{rpm}$ at $4^{\circ} \mathrm{C}$ for $20 \mathrm{~min}$, the supernatant was transferred to microtubes for enzyme assay and protein analysis. Protein contents of all the cell suspensions were determined according to the Bradford method. LDH activity was monitored spectrophotometrically (Shimadzo) at $30^{\circ} \mathrm{C}$ by measuring the increase in absorbance at $340 \mathrm{~nm}$. The assays were carried out in $0.2 \mathrm{M}$ Tris- $\mathrm{HCl}$ containing $55 \mathrm{mM}$ sodium lactate and $7 \mathrm{mM} \mathrm{NAD}^{+} \mathrm{Li}^{-}$. Creatine Kinase (CK) activity was measured spectrophotometrically by monitoring the NADPH absorbance change (at $340 \mathrm{~nm}$ ) based on a coupled assay. The assay was carried out in a mixture consisting of $186 \mathrm{mM}$ creatine phosphate, $2.4 \mathrm{mM}$ ADP, $110 \mathrm{mM}$ imidazole buffer, 21 $\mathrm{mM}$ glucose, $11 \mathrm{mM}$ Mg-acetate, $2.1 \mathrm{mM}$ EDTA, $6 \mathrm{mM}$ AMP, 12 $\mathrm{mM}$ diadenosine pentaphosphate, $2.4 \mathrm{mM}$ NADP, $2.5 \mathrm{U} / \mathrm{ml}$ hexokinase (HK), $1.5 \mathrm{U} / \mathrm{ml}$ glucose-6-phosphate dehydrogenase (G-6-PD), 24 $\mathrm{mM} \mathrm{N}$-acetylcysteine and anti-CK-M for CKMB (the isoform 

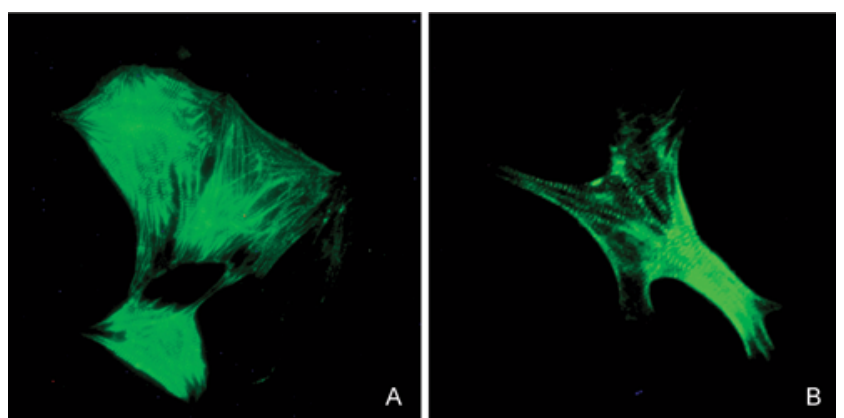

Fig. 1. Immunocytochemical pattern of $\alpha$-actinin staining in mouse ESC- (A) and neonatal- (B) derived cardiomyocytes.

having maximum specific activity in the heart) assay.

Apparent Michaelis-Menten constant $\left(K_{m}\right)$ and maximum catalytic rate $\left(V_{\max }\right)$ were calculated for ESC- and neonatal-derived cardiomyocytes by the Lineweaver-Burk method, using double reciprocal plots (Michaelis constant was measured over a substrate concentration range of $0.18-2 \mathrm{mM}$ for $\mathrm{LDH}$ and $0.8-10 \mathrm{mM}$ for $\mathrm{CK}$ ). The enzyme activity was calculated at seven substrate concentrations $\left(\mathrm{NAD}^{+}\right.$for $\mathrm{LDH}$ and $\mathrm{CrP}$ for $\mathrm{CK}$ ). Optimum $\mathrm{pH}$ was determined by carrying out enzyme activity at $30^{\circ} \mathrm{C}$ (for $\mathrm{LDH}$ ) and $37^{\circ} \mathrm{C}$ (for $\mathrm{CK}$ ). Moreover, optimum temperature was obtained by measuring enzyme activity at different temperatures ( $\mathrm{pH}$ was 9.0 and 6.5 for LDH and CK assay, respectively). The experiments were repeated at least three times. The data shown here are typyical experimental results.

\section{Results}

Cardiac differentiation was initiated by inducing EB formation, which adhered and continued to proliferate and differentiate into beating cardiomyocytes from day 6. ESC- and neonatalderived cardiomyosytes showed spindle, round and tri- or multiangular morphology with characteristic striations of sarcomeric structures of muscle cells. Immunocytochemistry revealed the presence of Z-disc specific protein, $\alpha$-actinin (Fig. 1). Other characteristics (cellular, molecular and ultrastructural) of these differentiated ESC-derived cardiomyocytes had been reported before (Baharvand et al., 2005).

Kinetic properties of cardiac enzymes, LDH and CK extracted from mouse ESC- and neonatal-derived cardiomyocytes showed the expression of the enzymes; they are summarized in Table-1. $K_{m}$ values of LDH toward NAD ${ }^{+}$were 0.37 and $0.69 \mathrm{mM}$ in ESC- and neonatal-derived cardiomyocytes, repectively (Fig. 2A). In addition, specific activity of LDH was $16.78 \mu \mathrm{mol} \mathrm{min}^{-1} \mathrm{mg}^{-1}$ (for ESC-derived cardiomyocytes) and $29.41 \mu \mathrm{mol} \mathrm{min}^{-1} \mathrm{mg}^{-1}$ (for neonatal-derived cardiomyocytes). Further experiments confirmed that the optimum $\mathrm{pH}$ was 8 for both LDH enzyme preparations (Fig. 2B). Optimum temperatures of LDH activity for ESC- and neonatal-derived cardiomyocytes were $65^{\circ} \mathrm{C}$ and $60^{\circ} \mathrm{C}$, respectively (Fig. 2C).

Specific activities of CK for $\mathrm{CrP}$ were 3.26 and $5.67 \mathrm{mM}$,
(A)

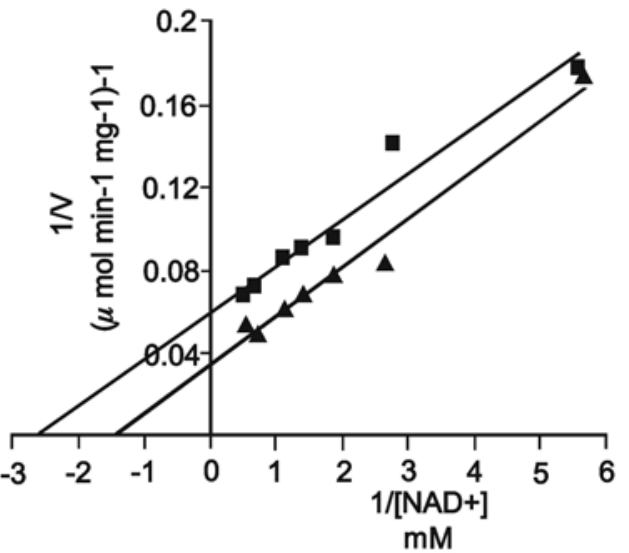

(B)

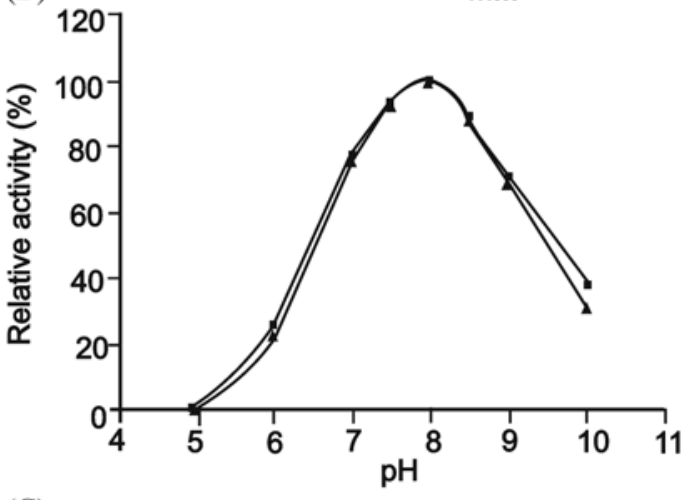

(C)

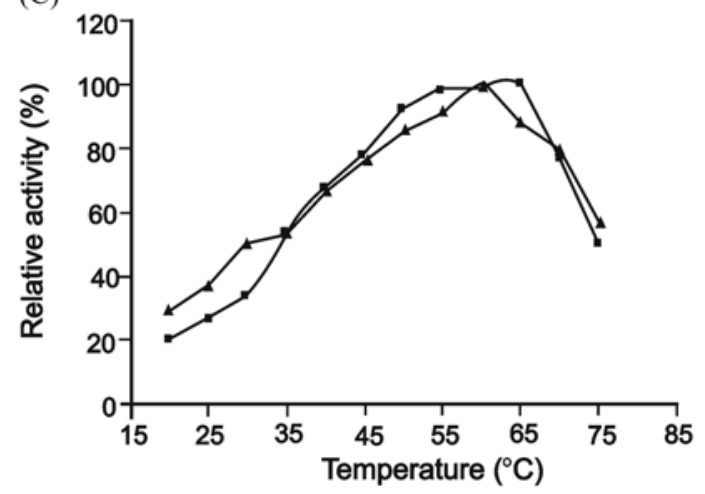

Fig. 2. Kinetic characteristics of $\mathrm{LDH}$ extracted from mouse ESC ( $\boldsymbol{\square})$ - and neonatal ( $\boldsymbol{\Delta}$ )-derived cardiomyocytes in forward reaction. (A) Lineweaver-Burk plot, (B) $\mathrm{pH}$ and (C) temperature profiles.

and its $K_{m}$ values toward $\mathrm{CrP}$ were 50.25 and $43.48 \mu \mathrm{mol}$ $\mathrm{min}^{-1} \mathrm{mg}^{-1}$ in ESC- and neonatal-derived cardiomyocytes, respectively (Fig. 3A). Optimum $\mathrm{pH}$ of $\mathrm{CK}$ activity was 7 for ESC- derived cardiomyocytes and 6.5 for neonatal-derived cardiomyocytes (Fig. 3B) . The optimum temperature of CK activity was $45^{\circ} \mathrm{C}$ for both enzyme preparations (Fig. 3C).

\section{Disscussion}

We demonstrated here the kinetic properties of metabolic enzymes involved in intracellular energy transport of mouse 
(A)

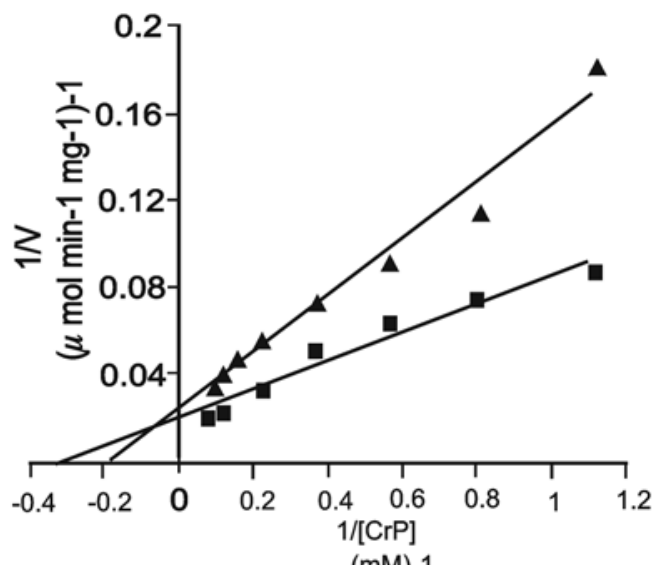

(B)

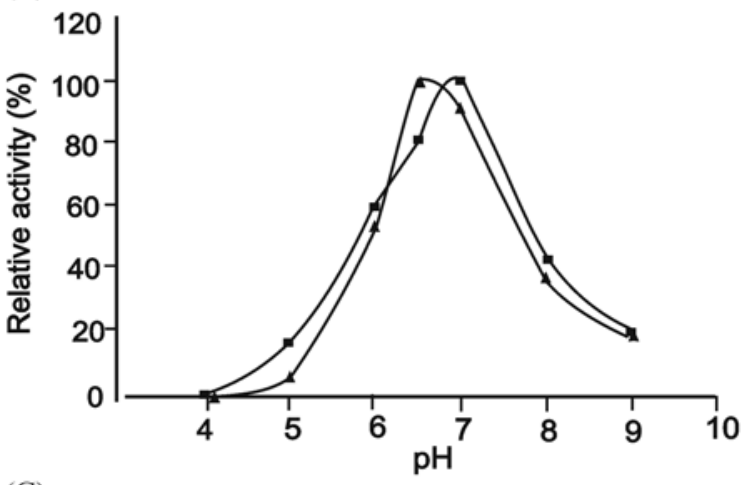

(C)

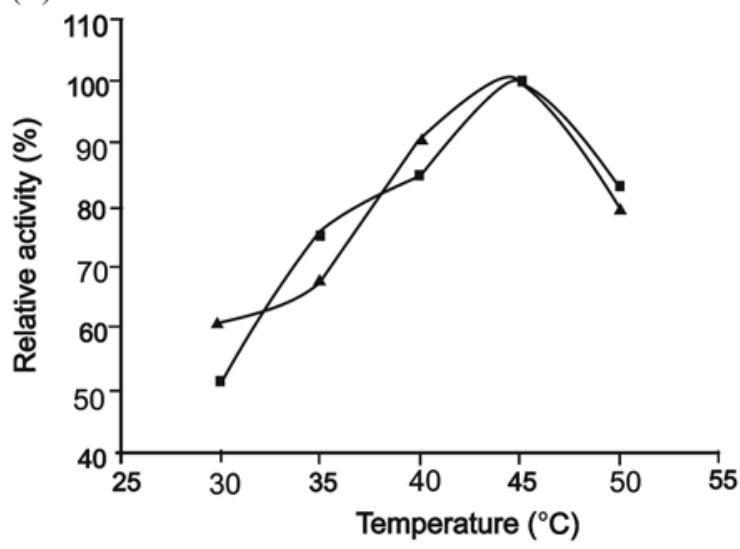

Fig. 3. Kinetic characteristics of CK extracted from mouse ESC ( $\boldsymbol{\square})$ - and neonatal ( $\mathbf{\Delta}$ )-derived cardiomyocytes in reverse reaction. (A) Lineweaver-Burk plot, (B) $\mathrm{pH}$ and (C) temperature profiles.

ESC- and neonatal-derived cardiomyocytes: LDH and CK. Our findings showed that ESC-derived cardiomyocytes expressed the same enzymes as natural cardiomyocytes do (Van Der Laarse et al., 1979). $K_{m}$ values of LDH toward $\mathrm{NAD}^{+}$in the present study were 0.37 and $0.69 \mathrm{mM}$ in ESCand neonatal-derived cardiomyocytes, respectively. The aforementioned findings are consistent with those reported in another study in which $K_{m}$ value of LDH toward NAD in the rat heart and human serum is $0.61 \mathrm{mM}$ and $0.56 \mathrm{mM}$, respectively (Yoshikkuni et al., 2001). Specific activity of
LDH in the present study was $16.78 \mu \mathrm{mol} \mathrm{min}^{-1} \mathrm{mg}^{-1}$ for ESC-derived cardiomyocytes and $29.41 \mu \mathrm{mol} \mathrm{min}^{-1} \mathrm{mg}^{-1}$ for neonatal-derived cardiomyocytes.

For creatine kinase, $K_{m}$ values toward CrP ESC- and neonatal-derived cardiomyocytes were 3.26 and $5.67 \mathrm{mM}$, respectively. The $K_{m}$ value toward $\mathrm{CrP}$ of $\mathrm{CK}$ was almost similar to that reported earlier (Szasz et al., 1976). In our investigation, specific activity of CK was 50.25 and 43.48

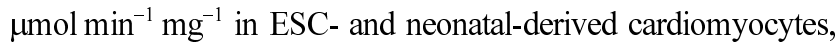
respectively. Lower $K_{m}$ of both enzymes for their substrates in the ESC-derived cardiomyocyts may be due to the difference in gene expression, developmental stage of maturation, environmental conditions and so forth (Singh and Kanungo, 1968; Granstrom and Magnusson, 1986; Lopaschuk et al., 1992; Saupe et al., 2000; Bass et al., 2001; Decking et al., 2001). For example, ESC-derived cardiomyocytes may not differentiate toward fully mature myocardium and exhibit gene expression and structural and functional properties consistent with early-stage cardiac tissue (Fijnvandraat et al., 2003). One possibility is that during cell maturation, the increasing contribution of oxidative phosphorylation to ATP production turns the cell into a compartmentalized system of energy production, so cardiac metabolism in vitro changes in response to oxygen and substrate availability and unknown cytoplasmic agentes; it is a complex process which involves maturation of mitochondria and condition of cell culture. Moreover, cardiac metabolism of adult homeotherms is almost exclusively aerobic. Fetal metabolism is primarily anaerobic, and this adaptive property is retained during the neonatal period.

Our data showed that the optimum $\mathrm{pH}$ for LDH was 8 for both enzyme preparations. In another study, optimum $\mathrm{pH}$ for crystaline enzyme is reported to be 9.0 (Winer et al., 1958); the same figure is 7.57 for the rat heart and 7.43 for human serum (Yoshikuni et al., 2001). In the present study, the observed optimum $\mathrm{pH}$ for $\mathrm{CK}$ was 6.5 (neonatal cardiomyocytes) and 7.0 (ESC-derived cardiomyocytes), which is similar to the figure reported earlier (Szasz et al., 1976). Similarity or discrepancy of opimum $\mathrm{pH}$ between ESC- and neonatalderived cardiomyocytes could be related to $\mathrm{pK}$ of different catalytic groups in the enzyme active site. $\mathrm{pH}$ can affect activity by changing the structure or by changing the charge on a residue functional in substrate binding or catalysis. The optimum temperatures of $\mathrm{LDH}$ in our study were $65^{\circ} \mathrm{C}$ and $60^{\circ} \mathrm{C}$ for ESC- and neonatal-derived cardiomyocytes, respectively; while similar investigations have reported the same figure to stand at $60^{\circ} \mathrm{C}$. Optimum temperature provides enough kinetic energy to overcome the energy of activation, so higher optimum temperature for LDH extracted from ESCderived cardiomyocytes can demonstrate higher stability of the three-dimentional structure of the enzyme and its need for high temperatures for providing maximum flexibility.

Taken together, ESC-differentiated cardiomyocytes displayed a model resembling the in vivo development of cardiomyocytes, yet it is important to overcome the limitations and the 
Table 1. Summarized kinetic properties of mouse ESC-and neonatal-derived cardiomyocytes

\begin{tabular}{lcccc}
\hline & \multicolumn{2}{c}{$\begin{array}{c}\text { CK characteristics in } \\
\text { cardiomyocytes derived from }\end{array}$} & \multicolumn{2}{c}{$\begin{array}{c}\text { LDH characteristics in } \\
\text { cardiomyocytes derived from }\end{array}$} \\
\cline { 2 - 5 } & Neonatal & ESC & Neonatal & ESC \\
$K_{m}(\mathrm{mM})$ & 5.67 & 3.26 & 0.69 & 0.37 \\
Specific activity $(\mathrm{U} / \mathrm{mg})$ & 50.25 & 43.48 & 29.41 & 16.78 \\
Optimum tempreture $\left({ }^{\circ} \mathrm{C}\right)$ & 45 & 45 & 60 & 65 \\
Optimum $\mathrm{pH}$ & 6.5 & 7 & 8 & 8 \\
\hline
\end{tabular}

challenges that remain. It is necessary to evaluate ESCderived cardiomyocytes in different developmental stages and in different conditions (e.g., in the presence of growth factors and extracellular matrix) and compare them with in vivoderived cardiomyocytes. Furthermore, although we tested the characteristics of ESC-derived cardiomyocytes in a crude extract condition, it is prefered to analyze the purified enzymes. In spite of these limitations, our results define some of the important characteristics of cardiomyocyte differentiation and should further facilitate the use of ESCs as an experimental model.

Acknowledgments We would like to thank Dr. Jürgen Hescheler (University of Koln, Germany) for his critical reading of the manuscript. We are also grateful to Dr. Abdoulhossein Shahverdi and Dr. Ahmad Vosugh for their support. Thanks are also due to Miss Taei, Mrs. MollaMohammadi and Mrs. Ghasemi for technical assistance. This work was supported by Royan Institute.

\section{References}

Baharvand, H., Azarnia, M., Parivar, K. and Ashtiani, S. K. (2005) The effect of extracellular matrix on embryonic stem cell-derived cardiomyocytes. J. Mol. Cell. Cardio. 38, 495-503.

Baharvand, H. and Matthaei, K. (2004) Culture condition difference for establishment of new embryonic stem cell lines from the $\mathrm{C} 57 \mathrm{BL} / 6$ and $\mathrm{BALB} / \mathrm{C}$ mouse strains. In vitro cell. Dev. Biol.-Animal. 40, 76-81.

Bass, A., Stejskalova, M., Stieglerova, A., Ostadal, B. and Samanek, M. (2001) Ontogenetic development of energysupplying enzymes in rat and guinea-pig heart. Physiol Res. 50, 237-245.

Chlopcikova, S., Psotova, J. and Miketova, P. (2001) Neonatal, rat cardiomyocytes-A model for the study of morphological, biochemical and electrophysiological characteristic of the heart. Biomed. Papers. 145, 49-55.

Dawson, D. M., Eppenberger, H. M. and Kaplan, N. O. (1967) The coparative enzymology of creatin kinase . II. Physical and chemical properties. J. Biol. Chem. 242, 210-217.

Decking, U. M., Alves, C., Wallimann, T., Wyss, M. and Schrader, J. (2001) Functional aspects of creatine kinase isoenzymes in endothelial cells . Am. J. Physiol. Cell. Physiol. 281, 320-328.

Evans, M. J. and Kaufman, M. H. (1981) Establishment in culture of pluripotent cells from mouse embryos. Nature. 292, 154156.

Fijnvandraat, A. C., van Ginneken, A. C., de Boer, P. A., Ruijter, J. M., Christoffels, V. M., Moorman, A. F. and Lekanne Deprez, R. H. (2003) Cardiomyocytes derived from embryonic stem cells resemble cardiomyocytes of the embryonic heart tube. Cardiovasc Res. 58, 399-409.

Granstrom, G. and Magnusson, B. C. (1986) Lactate dehydrogenase isoenzyme changes during facial development. J. Anat. 148, 183-192.

Hescheler, J., Fleischmann, B. K., Lentini, S., Maltsev, V. A., Rohwedel, J., Wobus, A. M. and Addicks, K. (1997) Embryonic stem cell:a model to study structural and functional properties in cadiomyogenesis. Cardiovasc Res. 36, 149-162.

Kenneth, R., Czyz, J., Tweedle, D. and Tian Yang, H. (2002) Differentiation of pluripotent embryonic stem cell into cardiomyocytes. Circ. Res. 91, 189-201.

Labosky, P. A., Barlow, D. P. and Hogan, B. L. (1994) Mouse embryonic germ $(E G)$ cell lines: transmission through the germ line and differences in the methylation imprint of insulin-like growth factor 2 receptor (Igf2r) gene compared with embryonic stem (ES) cell lines. Development. 120, 3197-3204.

Li, S.S. (1998) Structure, regulation and evolution of vertebrate lactate dehydrogenase genes. Zoological Studies. 37, 1-6.

Lopaschuk, G. D., Collins-Nakai, R. I. and Itoi, T. (1992) Developmental changes in energy substrate use by the heart. Cardiovasc Res. 26, 1172-1180.

Maltsev, V. A., Rohewedel. J., Hescheler, J. and Wobous, A. M. (1993) Embryonic stem cell differentiate in vitro into cardiomyocytes representing sinusnodal, artial and ventricular cell types. Mech. Dev. 44, 41-50.

Maltsev, V. A., Wobus, A. M., Rohwedel, J., Bader, M. and Hescheler, J. (1994) Cardiomyocytes differentiated in vitro from embryonic stem cell developmentally express cardicspesific genes and ionic currents. Circ Res. 75, 233-244.

Martin, G. R. (1981) Isolation of a pluripotent cell line from early mouse embryos cultured in medium conditioned by teratocarcinoma stem cell. Proc. Natl. Acad. Sci. USA 78, 7634-7638.

Saks, V. A., Kupriyanov, V. V. and Elizarova, G. V. (1980) Studies of energy transport in heart cells. J. Biol. Chem. 255, 755-763.

Saupe, K. W., Spindler, M., Hopkins, J. C., Shen, W. and Ingwall, J. S. (2000) Kinetic, thermodynamic, and developmental consequences of deleting creatine kinase isoenzymes from the heart. Reaction kinetics of the creatine kinase isoenzymes in the intact heart. J. Biol. Chem. 275, 19742-19746.

Singh, S. N. and Kanungo, M. S. (1968) Alterations in lactate dehydrogenase of the brain, heart, skeletal muscle, and liver of 
rats of various ages. J. Biol. Chem. 243, 4526-4529.

Smith, A. G. (2001) Embryo-derived stem cells: of mice and men. Annu. Rev. Cell. Dev. Biol. 17, 435-462.

Szasz, G., Gruber, W. and Bernt, E. (1976) Creatine kinase in serum:1.Determination of optimum reaction condition . Clin. Chem. 22, 650-656.

Thomson, J. A., Itskovitz-Eldor, J., Shapiro, S. S., Waknitz, M. A., Swiergiel, J. J., Marshall, V. S. and Jones, J. M. (1998) Embryonic stem cell lines derived from human blastocysts. Science 282, 1145-1147.

Van Der Laarse, A., Hollar, L., Kokshoon, L. J. and Witteveen, S.
(1979) The activity of cardio-specific isoenzymes of creatine phosphokinase and lactate dehydrogenase in monolayer cultures of neonatal rat heart. J. Mol. Cel. Cardio. 11, 501-510.

Winer, A. D. and Schwert, G. W. (1958) Lactic dehydrogenase. IV. The influence of $\mathrm{pH}$ on the kinetics of the reaction. J. Biol. Chem. 231, 1065-1083.

Yoshikuni, K., Matsuda, T., Xia, W. L., Inagaki, M., Nishimura, M. and Tanishima, K. (2001) Cold lability of lactate dehydrogenase isoenzymes and the effective preparation of reference material for clinical laboratory use. Biotechnol. Appl. Biochem. 34, 167-171. 